\title{
Clinical efficacy of coil embolization in treating pseudoaneurysm post-Whipple operation
}

\author{
HAO XU ${ }^{1}$, CONG JING $^{1}$, JIE ZHOU ${ }^{2}$, XULI MIN ${ }^{1}$, JING ZHAO $^{1}$, LIN YANG $^{1}$ and YONGJUN REN ${ }^{1}$ \\ ${ }^{1}$ Sichuan Key Laboratory of Medical Imaging, Department of Interventional Radiology, \\ ${ }^{2}$ Department of Hepatobiliary Surgery, Affiliated Hospital of North Sichuan Medical College, \\ Nanchong, Sichuan 637000, P.R. China
}

Received October 3, 2019; Accepted June 24, 2020

DOI: $10.3892 / \mathrm{etm} .2020 .9164$

\begin{abstract}
The present study aimed to evaluate the clinical efficacy and safety of angiography and coil embolization for pseudoaneurysm post-pancreatoduodenectomy (PD). A total of 17 patients with gastrointestinal or abdominal hemorrhage after PD were included in the present study. Angiography was performed on the celiac artery, common hepatic artery, splenic artery, gastroduodenal artery and superior mesenteric artery to determine the size of the pseudoaneurysm, the parent artery and its collateral branches. A variety of embolization techniques have been applied to embolize pseudoaneurysm, including the sac packing technique, proximal embolization, exclusion technique and sandwich technique. Different techniques with coils were used for embolization and the clinical effects of embolization were analyzed. A total of 18 pseudoaneurysms were identified in 17 patients. In 2 patients, severe technical complications occurred, including migration of the coil and rupture of pseudoaneurysm, and one of them died, which may have been associated with this complication. No serious clinical complications were observed in the other patients. A total of 7 patients had mild clinical complications, including mild abdominal and dorsal pain, which were alleviated after symptomatic management. A total of 15 patients with definite pseudoaneurysm were successfully embolized without re-bleeding and complications. The clinical success rate was $94.1 \%$ (16/17). In conclusion, a variety of embolization techniques may be applied for the treatment of pseudoaneurysm after PD, which have high technical and clinical success rates and small trauma. It is recommended in emergency situations, but care should be taken to avoid serious technical complications.
\end{abstract}

Correspondence to: $\mathrm{Dr} \mathrm{Hao} \mathrm{Xu}$, Sichuan Key Laboratory of Medical Imaging, Department of Interventional Radiology, Affiliated Hospital of North Sichuan Medical College, 63 Wenhua Road, Nanchong, Sichuan 637000, P.R. China

E-mail: xuhao_niu@163.com

Key words: pancreatoduodenectomy, pseudoaneurysm, Whipple operation, bleeding

\section{Introduction}

Pancreaticoduodenectomy (PD), first performed in 1909, was popularized by the American surgeon Professor Allen Whipple and is therefore known as 'Whipple operation' $(1,2)$. PD is the standard surgical procedure for treating periampullary tumors (including ampullary carcinoma, duodenal adenocarcinoma and distal bile duct cancer) and pancreatic head carcinoma and includes two surgical approaches: Transabdominal PD and laparoscopic PD $(3,4)$. PD has been historically considered to be the most complex and promising procedure (5). Particularly in recent years, the minimally-invasive PD technique has been extensively performed and accepted as an effective method for treating pancreatic lesions (6). However, the complications post-PD, including bleeding, pseudoaneurysm, arteriovenous fistula, infection, have constantly impeded the development of Whipple operation (7). Among the above-mentioned complications, delayed post-pancreatectomy hemorrhage $(\mathrm{PPH})$ is one of the relatively severe vascular adverse events, which is usually caused by rupture of pseudoaneurysm (8). The pseudoaneurysm is frequently caused by the pancreatic fistula (PF) and injuries in the surgical processes. Although pseudoaneurysm-induced bleeding is rare in clinical practice, it has serious consequences if patients receive improper treatment or delayed intervention. Furthermore, a lack of proficient laparoscopic skills and training experience have also impeded the development and application of Whipple operation (9). However, there is insufficient data to indicate that surgeons who lack proficient laparoscopic skills and experience of the surgeons will lead to higher complications.

Embolization therapy has been proven to be a critical strategy for managing patients suffering from cardiovascular diseases and surgical bleeding $(10,11)$. In the last decade, embolization therapy has been widely used in the treatment of post-operative bleeding and delayed PPH caused by pseudoaneurysm (12); however, these pseudoaneurysms are managed by exploration in patients with hemodynamically stable conditions. Ligation, pseudoaneurysm resection and removal of the involved organ are the main methods of surgical exploration (12). Therefore, in the present study, the experience of intervention treatment for pseudoaneurysm post-PD at our hospital was retrospectively analyzed. The safety and clinical efficacy of angiography and coil 
embolization in the treatment of pseudoaneurysm after PD were investigated.

\section{Materials and methods}

Patients. The present retrospective study analyzed 17 patients (5 females and 12 males) undergoing PD, which was followed by PPH caused by pseudoaneurysm, between May 2011 and May 2018 at the Affiliated Hospital of North Sichuan Medical College (Nanchong, China). Detailed information on the patients is listed in Table I. The mean age of the patients was $61.35 \pm 8.95$ years and the time between surgery and PPH was $7.41 \pm 4.56$ days. The cohort comprised 13 cases of pancreatic head carcinoma, 1 case of adenocarcinoma of the duodenum and 3 cases of distal bile duct cancer.

The present study was approved by the Ethics Committee of the Affiliated Hospital of North Sichuan Medical College [Nanchong, China; file no. 2019ER(A)09-02]. The treatment methods, including exploration stent implantation and coil embolization, were communicated to the patients and their families. Due to economic factors and medical insurance of the patients, coil embolization was chosen. All patients explicitly consented to receiving this treatment.

Inclusion and exclusion criteria. The inclusion criteria were as follows: i) Patients presented with symptoms of gastrointestinal or abdominal bleeding after the Whipple operation; ii) patients without contraindications underwent emergency arteriography or embolization therapy; iii) no distant metastasis. The following exclusion criteria were applied: i) Death due to peri-operative complications; ii) diagnosis with peritoneal cancer; iii) patients who underwent angiography without embolization with coils.

Arteriography and embolization therapy. The Seldinger technique was used to percutaneously puncture the femoral artery and insert a $5 \mathrm{~F}$ catheter sheath. To assess the condition of the artery of the digestive tract, abdominal aortography was performed with a pigtail catheter. Subsequently, a $5 \mathrm{~F}$ catheter was inserted into the celiac, common hepatic, splenic, gastroduodenal (GDA), superior and inferior mesenteric arteries in all patients for angiographic analysis to determine the location of the pseudoaneurysm(s) and the diameter of the parent artery and collateral vessels. If any active bleeding or pseudoaneurysm was detected, a 2.5F microcatheter (Renegade ${ }^{\mathrm{TM}} \mathrm{STC18}$; Boston Science) was inserted into the target artery using a coaxial catheter technique for super-selective angiography and embolization. Various techniques are described for embolization of a pseudoaneurysm using Tower or Diamond coils (Boston Vort $\mathrm{X}^{\mathrm{TM}}-18$ platinum coil or VortX ${ }^{\mathrm{TM}}-18$ Diamond platinum coil; 0.018 inches; Boston Science) and/or a detachable coil embolization system (Interlock Fibered IDC occlusion system, 0.018 inches; Boston Scientific). The commonly used methods of embolization of pseudoaneurysms included simple lumen embolization (sac packing technique), proximal embolization of the parent artery (proximal embolization technique), inflow and outflow embolization of the parent artery (exclusion technique or isolation technique) and efferent artery embolization + sac packing/aneurysmal neck packing + afferent artery embolization (sandwich technique) (13). Sac packing is performed for saccular pseudoaneurysms with a narrow neck, which allows for retention of coils within the sac maintaining the patency of the parent artery. Proximal embolization of the parent artery is applied to pseudoaneurysms at the end of arterioles, including or excluding pack of sac, which is essentially a special exclusion technique. The exclusion technique is used for those pseudoaneurysms with a small size, wide neck and short landing zone, which refers to the area of proximal and distal stent placement and vascular remodeling. The sandwich technique is performed for pseudoaneurysms that are likely to have collateral inflow and outflow arteries.

Post-operative evaluation and follow-up. The definition of bleeding and severity was according to the Standard of International Study Group for Pancreatic Surgery (14). The definitions and evaluation criteria on the efficacy, as well as technical and clinical success of embolization, were according to the Society of Interventional Radiology guidelines (15). Achievement of hemostasis, disappearance of the pseudoaneurysm or the occlusion of the parent artery were considered indicative of technical success (15). Clinical success referred to the absence of acute bleeding symptoms, stable hemodynamics, hemoglobin decrease of no more than $15 \mathrm{~g} / \mathrm{l}$, no requirement to infuse suspended red blood cells, no blood fluid in the drainage tube and no re-angiography or embolization (16-18). Technical complications included non-target vascular embolism, iatrogenic vascular injury, puncture site bleeding, rupture of the pseudoaneurysm, rupture of the parent artery, arterial dissection, distal migration of the coil and straight deployment of the coil. Clinical complications included post-embolization complications (secondary infection) and embolization syndrome (pain, fever, liver dysfunction and vomiting). Technical and clinical success were the major endpoints of embolization (19-21). The short-term clinical outcome was evaluated according to the following points: Whether symptoms of abdominal pain or fever were present, vital signs, bleeding and dynamic monitoring of hemoglobin. The long-term clinical outcome was evaluated according to the following points: Occurrence of re-bleeding, heterotopic embolism caused liver failure or gastrointestinal ischemic necrosis.

\section{Results}

Arteriography presentation and embolization therapy. A total of 18 pseudoaneurysms were detected in 17 patients. The types of primary diseases, time between surgery and PPH, bleeding time and area, number of pseudoaneurysms, technical and clinical complications and therapeutic outcomes of all 17 patients are shown (Table I) The angiographic findings of pseudoaneurysm were cystic, round or irregular nodular, with spasm and rigidity of the parent artery in the vast majority of cases (17/18; Figs. 1 and 2). Indirect signs of arteriography were irregular and rigid morphology of the transitional area of the common hepatic artery and the proper hepatic artery, with small notches (Figs. 3 and 4). Sentinel hemorrhage was detected in all patients but there was no sign of active hemorrhage at the time of angiography. There were 17 cases of pseudoaneurysm, including 15 cases with the pseudoaneurysm located at the main trunk and branches of the GDA, 1 case with location in 
Table I. Details of the patients with bleeding and PsA post-Whipple operation.

\begin{tabular}{|c|c|c|c|c|c|c|c|c|}
\hline $\begin{array}{l}\text { Patient } \\
\text { no./sex }\end{array}$ & $\begin{array}{c}\text { Age } \\
\text { (years) }\end{array}$ & $\begin{array}{l}\text { Bleeding } \\
\text { time } \\
\text { (days) }\end{array}$ & $\begin{array}{l}\text { Pathological } \\
\text { diagnosis }\end{array}$ & Bleeding area & $\begin{array}{l}\text { PsAs } \\
\text { (n) }\end{array}$ & $\begin{array}{c}\text { Technical } \\
\text { complications }\end{array}$ & $\begin{array}{c}\text { Clinical } \\
\text { complications }\end{array}$ & $\begin{array}{c}\text { Therapeutic } \\
\text { outcome }\end{array}$ \\
\hline $1 /$ female & 63 & 5 & $\begin{array}{l}\text { Duodenal } \\
\text { adenocarcinoma }\end{array}$ & Digestive tract & 2 & $\begin{array}{c}\text { Distal } \\
\text { migration }\end{array}$ & - & Cure \\
\hline $2 /$ male & 57 & 7 & $\begin{array}{l}\text { Pancreatic head } \\
\text { carcinoma }\end{array}$ & Digestive tract & 1 & - & - & Cure \\
\hline $3 /$ male & 74 & 2 & $\begin{array}{l}\text { Pancreatic head } \\
\text { carcinoma }\end{array}$ & $\begin{array}{l}\text { Digestive } \\
\text { tract/abdominal cavity }\end{array}$ & 1 & - & - & Cure \\
\hline $4 /$ male & 71 & 2 & $\begin{array}{l}\text { Pancreatic head } \\
\text { carcinoma }\end{array}$ & $\begin{array}{l}\text { Digestive } \\
\text { tract/abdominal cavity }\end{array}$ & 1 & $\begin{array}{c}\text { Rupture of } \\
\text { GDA }\end{array}$ & $\begin{array}{l}\text { Liver } \\
\text { dysfunction }\end{array}$ & Death \\
\hline 5/female & 60 & 9 & $\begin{array}{l}\text { Pancreatic head } \\
\text { carcinoma }\end{array}$ & $\begin{array}{l}\text { Digestive } \\
\text { tract/abdominal cavity }\end{array}$ & 1 & - & - & Cure \\
\hline $6 /$ male & 43 & 12 & $\begin{array}{l}\text { Pancreatic head } \\
\text { carcinoma }\end{array}$ & $\begin{array}{l}\text { Digestive } \\
\text { tract/abdominal cavity }\end{array}$ & 1 & - & - & Cure \\
\hline 7/male & 55 & 3 & $\begin{array}{l}\text { Pancreatic head } \\
\text { carcinoma }\end{array}$ & $\begin{array}{l}\text { Digestive } \\
\text { tract/abdominal cavity }\end{array}$ & 1 & - & - & Cure \\
\hline $8 /$ male & 52 & 6 & $\begin{array}{l}\text { Pancreatic head } \\
\text { carcinoma }\end{array}$ & $\begin{array}{l}\text { Digestive } \\
\text { tract/abdominal cavity }\end{array}$ & 1 & - & - & Cure \\
\hline 9/male & 53 & 8 & $\begin{array}{l}\text { Pancreatic head } \\
\text { carcinoma }\end{array}$ & $\begin{array}{l}\text { Digestive } \\
\text { tract/abdominal cavity }\end{array}$ & 1 & $\begin{array}{l}\text { Distal } \\
\text { migration and } \\
\text { rupture of } \\
\text { parent artery }\end{array}$ & $\begin{array}{l}\text { Liver } \\
\text { dysfunction }\end{array}$ & Cure \\
\hline $10 /$ female & 59 & 13 & $\begin{array}{l}\text { Distal bile duct } \\
\text { cancer }\end{array}$ & $\begin{array}{l}\text { Digestive } \\
\text { tract/abdominal cavity }\end{array}$ & 1 & - & Pain & Cure \\
\hline $11 /$ male & 64 & 17 & $\begin{array}{l}\text { Pancreatic head } \\
\text { carcinoma }\end{array}$ & Digestive tract & 1 & - & Vomiting & Cure \\
\hline $12 /$ male & 72 & 4 & $\begin{array}{l}\text { Pancreatic head } \\
\text { carcinoma }\end{array}$ & $\begin{array}{l}\text { Digestive } \\
\text { tract/abdominal cavity }\end{array}$ & 1 & - & - & Cure \\
\hline $13 /$ male & 64 & 9 & $\begin{array}{l}\text { Pancreatic head } \\
\text { carcinoma }\end{array}$ & $\begin{array}{l}\text { Digestive } \\
\text { tract/abdominal cavity }\end{array}$ & 1 & - & - & Cure \\
\hline 14/female & 56 & 5 & $\begin{array}{l}\text { Distal bile duct } \\
\text { cancer }\end{array}$ & $\begin{array}{l}\text { Digestive } \\
\text { tract/abdominal cavity }\end{array}$ & 1 & - & Vomiting & Cure \\
\hline $15 /$ male & 78 & 3 & $\begin{array}{l}\text { Pancreatic head } \\
\text { carcinoma }\end{array}$ & $\begin{array}{l}\text { Digestive } \\
\text { tract/abdominal cavity }\end{array}$ & 1 & - & Fever & Cure \\
\hline $16 /$ male & 57 & 6 & $\begin{array}{l}\text { Distal bile duct } \\
\text { cancer }\end{array}$ & $\begin{array}{l}\text { Digestive } \\
\text { tract/abdominal cavity }\end{array}$ & 1 & - & - & Cure \\
\hline 17/female & 65 & 15 & $\begin{array}{l}\text { Pancreatic head } \\
\text { carcinoma }\end{array}$ & $\begin{array}{l}\text { Digestive } \\
\text { tract/abdominal cavity }\end{array}$ & 1 & - & - & Cure \\
\hline
\end{tabular}

Abdominal hemorrhage refers to the drainage of hemorrhage fluid by plasma drainage tube. Gastrointestinal bleeding refers to hematemesis or hematochezia or both. PsA, pseudoaneurysm.

the common hepatic artery (Fig. 3A), 1 case with location in the stump of the GDA (Fig. 4A) and 1 case with location of the pseudoaneurysm in the major splenic artery.

In one patient, two pseudoaneurysms were located in different branches of the GDA, who underwent a combination of the proximal embolization and exclusion techniques
(Fig. 1). In 16 pseudoaneurysms, the sandwich or exclusion technique were used for embolization, where good therapeutic effects were achieved, as exemplified by a representative case with arteriography images provided in Fig. 2. Furthermore, 1 patient had perihepatic hematocele and the liver was compressed to the midline. Considering the large 

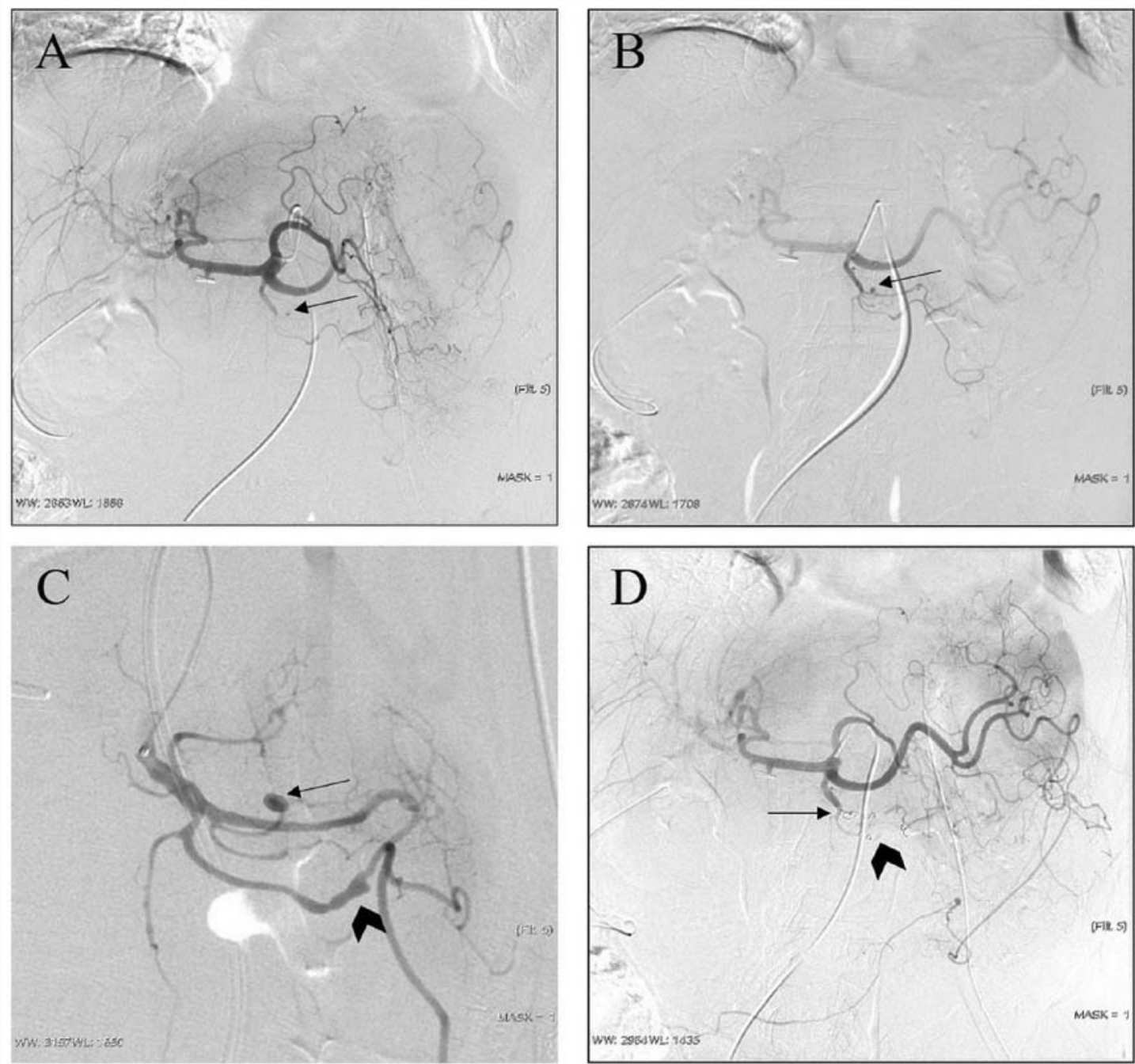

Figure 1. Representative case of a 63-year-old female patient (case no. 1; Table I) diagnosed with duodenal adenocarcinoma. (A) Digital subtraction angiography images indicated a suspected pseudoaneurysm (arrow) in one branch of the gastroduodenal artery, which was confirmed as a saccular pseudoaneurysm (arrow) by (B) superselective catheterization to gastroduodenal arteriography. (C) Another irregular pseudoaneurysm is found by local magnification angiography (arrow). (D) A proximal embolization technique and exclusion technique were used, respectively, since the pseudoaneurysms arose from the end of a branch (arrow) and a branch with both inflow and outflow of the parental artery (arrowhead).
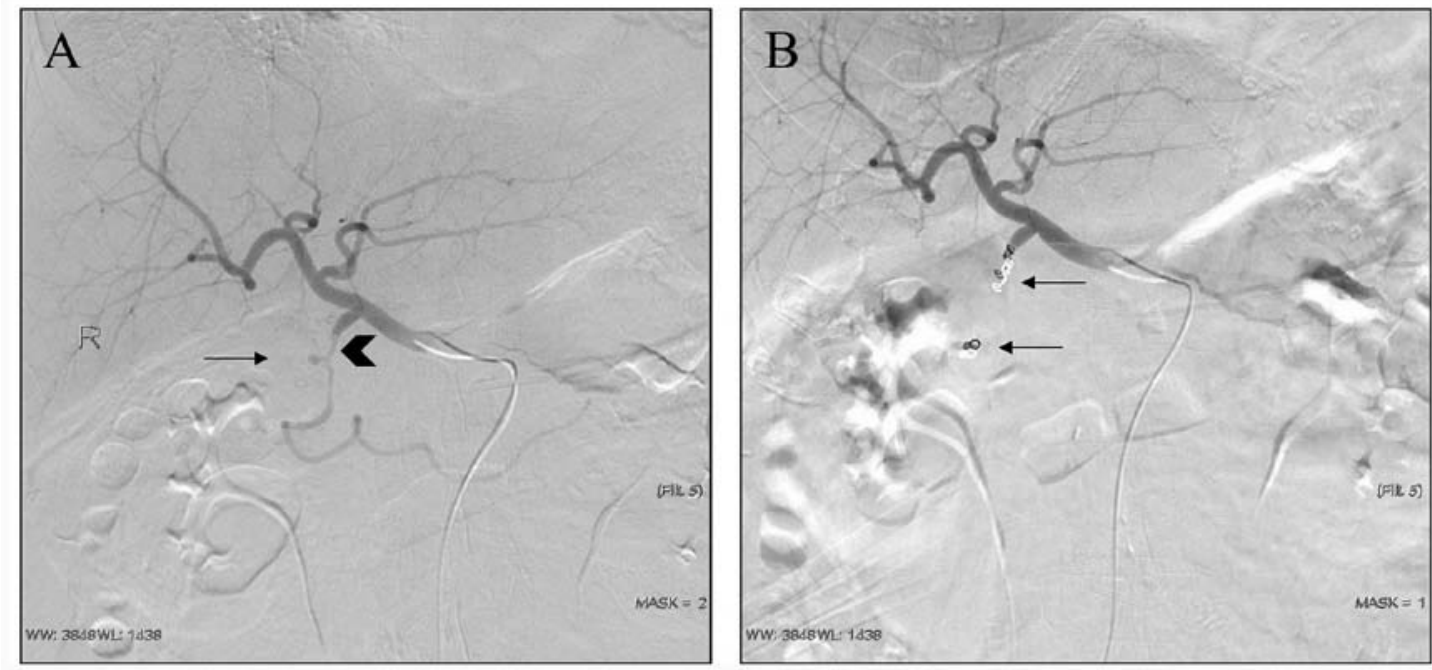

Figure 2. Representative case of a 57-year-old male patient (case no. 2; Table I) diagnosed with pancreatic head cancer. (A) Digital subtraction angiography indicated a short-necked pseudoaneurysm (arrow) arising from the GDA, which was irregular and spasmodic (arrowhead). (B) An exclusion technique, i.e. embolization of the inflow and outflow embolization of the parent artery (arrow) was used, since the pseudoaneurysm arose from the main trunk of the GDA, which had collateral supply. GDA, gastroduodenal artery. 

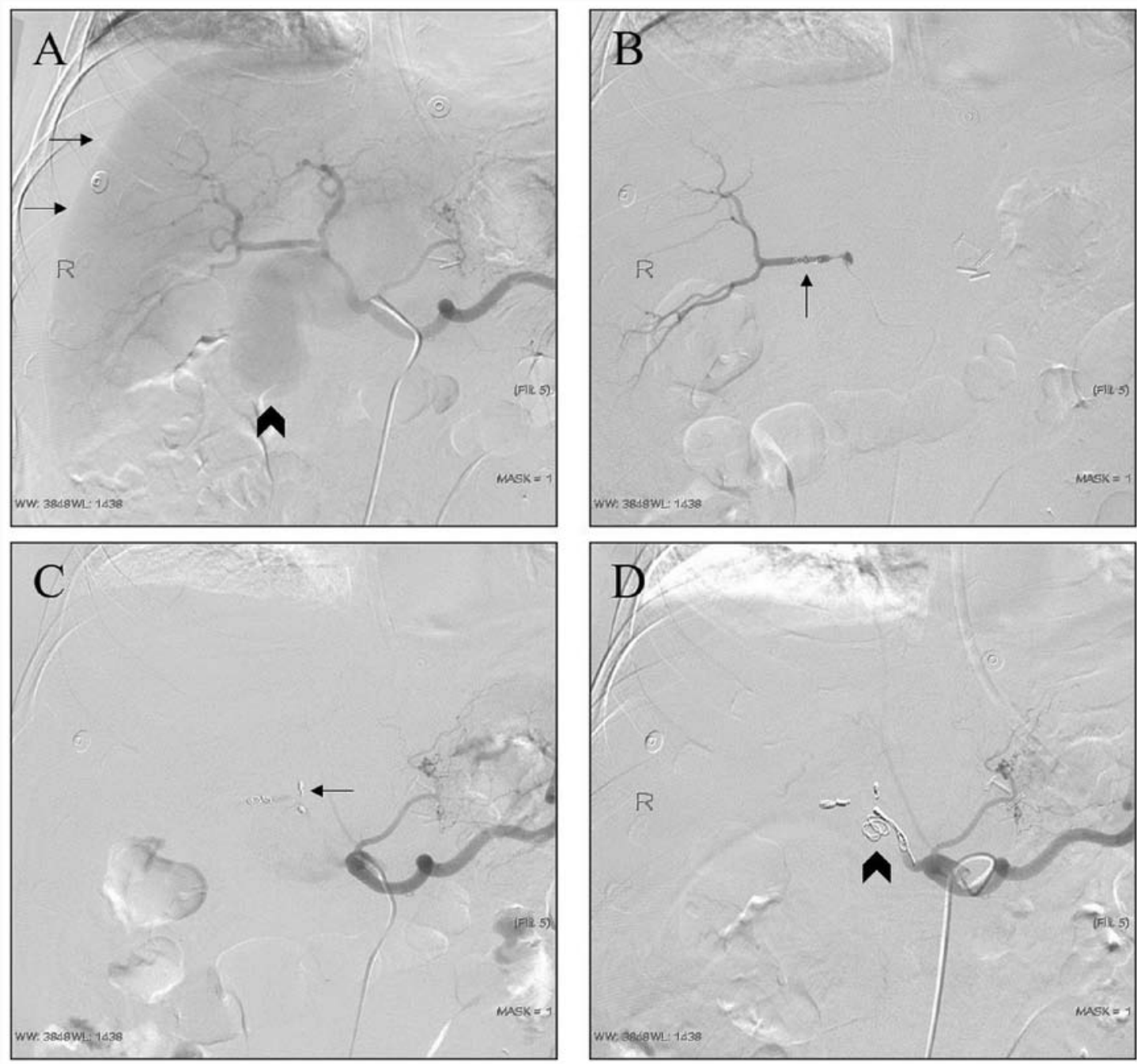

Figure 3. Representative case of a 74-year-old male patient (case no. 3; Table I) diagnosed with pancreatic head cancer. (A) Arteriography indicated a large-size pseudoaneurysm (arrowhead) arising from the hepatic artery. At the same time, subcapsular blood or fluid was visible and the liver was compressed and shifted inwards (arrows). (B) An exclusion technique was used for embolization. (C) Coil migration (arrows) occurred when embolization of the end of the proper hepatic artery was performed. (D) The coil protruded out of the vascular cavity during proximal embolization, which was considered as the parent artery rupture or penetration into the pseudoaneurysm (arrowhead).

size of the pseudoaneurysm, the risk of rupture of the pseudoaneurysm and the progressive decrease of hemoglobin, the exclusion technique was used directly after arteriography (Fig. 3). In one case, angiography revealed an irregular GDA stump and an adjacent hepatic artery, which was considered as a residual saccular pseudoaneurysm. Considering that the patient had blood in the abdominal drainage tube and no active bleeding was detected on arteriography, the sac packing technique was used for GDA stump embolization. Angiography revealed that the coil was in a good position and the operation was completed (Fig. 4B). However, during the extraction of the catheter, the patient complained of abdominal pain, which was followed by a significant drop in blood pressure. Emergency re-angiography revealed that the GDA pseudoaneurysm ruptured and bled, and the sandwich technique was performed to embolize the proper hepatic artery and common hepatic artery (Fig. 4). Despite aggressive symptomatic treatment, the patient died 1 week later from causes including insufficient blood volume and liver failure.
Technique, clinical complications and success. In one patient, serious technical complications of pseudoaneurysm rupture occurred, which resulted in death. Another patient presented with the technical complication of coil migration, but it did not cause any serious clinical complications. No serious clinical complications occurred in any of the other patients. A total of 7 patients had mild clinical complications, including mild abdominal and dorsal pain, which was alleviated by symptomatic management. In total, 15 patients with definite pseudoaneurysms were successfully embolized without re-bleeding and complications. The success rate of hemostasis was $94.1 \%(16 / 17)$.

\section{Discussion}

PD has been widely used for treating pancreatic head cancer and periampullary cancers; however, the complications still hinder the further development of Whipple operation (22). Post-operative complications include postoperative pancreatic fistula (POPF), hemorrhage, pseudoaneurysm 

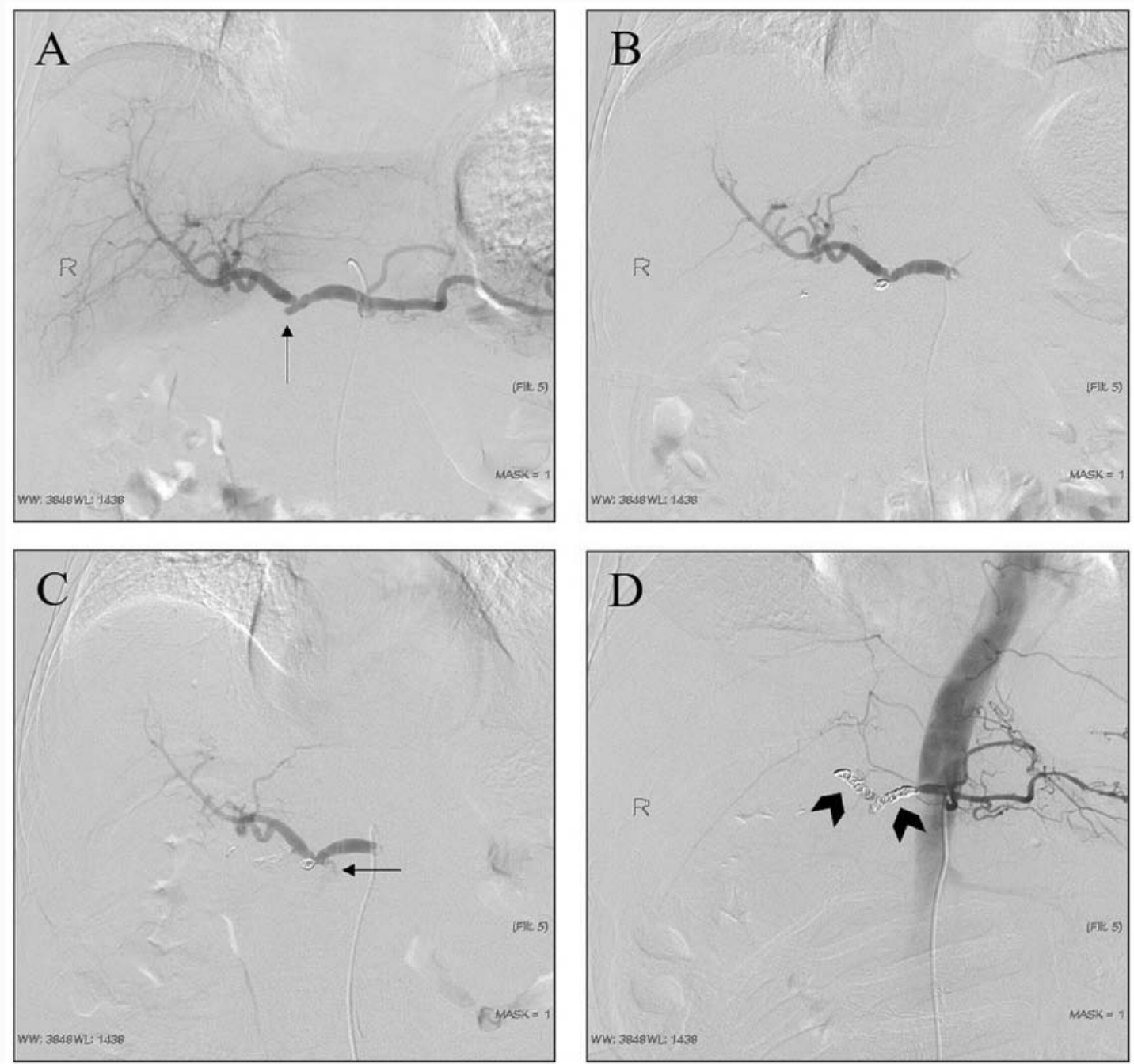

Figure 4. Representative case of a 71-year-old male patient (case no. 4; Table I) diagnosed with pancreatic head cancer. Sentinel hemorrhage was considered. (A) Arteriography indicated that a residual saccular pseudoaneurysm arose from the gastroduodenal artery stump (arrow). (B) The sac packing technique was used. During the extraction of the catheter, the patient complained of abdominal pain, which was followed by a significant drop in blood pressure. (C) Re-angiography confirmed active bleeding (arrow), which was considered to arise from pseudoaneurysm rupture. Therefore, (D) the sandwich technique was adopted for remedial treatment (arrowheads).

and arteriovenous fistula. Delayed post-pancreatectomy bleeding refers to the bleeding at $>24 \mathrm{~h}$ post-PD $(17,23)$. The incidence of post-pancreatectomy bleeding has been estimated to be $4-16 \%$ and the mortality rate may be as high as $50 \%$ within 1-4 weeks (24-26). In the present study, the mean bleeding time post-PD was $\sim 7$ days, but no clinical manifestations such as re-bleeding appeared post-embolization. Among numerous factors affecting the safety of PD, POPF is the most important risk factor. For patients with periampullary cancer, which includes duodenal, ampullary and distal bile duct cancers, they exhibit similar clinical symptoms and require similar treatment strategies compared with pancreatic head carcinoma $(27,28)$. However, pancreatic fistula after PD for pancreatic head carcinoma is more dangerous and may cause arterial rupture and bleeding $(29,30)$. With the improvement of surgery, a variety of modified Whipple operations (such as pylorus-preserving PD) has been widely used and the complications are gradually reduced (27). However, due to the gap in resources between Eastern and Western China in terms of medical development, the classic (Whipple's) PD is still the major treatment strategy at our hospital, and therefore, its complications, including POPF and bleeding, are not rare. POPF is the most common and serious complication of pancreatic surgery. No matter which type of operation is used, the incidence of POPF is as high as $20-40 \%(31,32)$. It is not uncommon for trypsin to erode and digest the peripancreatic artery and cause pseudoaneurysm. Electrotome and ultrasound scalpel may damage adventitia and result in pseudoaneurysm during lymph node removal. In the process of tissue dissection, it is inevitable to clamp the tissue, resulting in arterial and venous damage. Together, the above-mentioned risk factors are common causes of bleeding and pseudoaneurysm post-Whipple procedures. In addition, in our experience, slippage of the ligation line of the gastroduodenal stump may also be an important cause of bleeding (33).

Abdominal pain, abdominal distension, abdominal hemorrhage, hematemesis and hematochezia are common clinical symptoms of pseudoaneurysm rupture and bleeding, while sentinel bleeding is generally regarded as a precursor of massive hemorrhage (34). CT angiography is valuable in the diagnosis 
of pseudoaneurysms with a sensitivity rate of $95 \%(35,36)$. However, most of the patients with early hemorrhage are not suitable to undergo this type of imaging because of their critical and urgent condition $(35,36)$. Selective celiac angiography is the gold standard for the diagnosis of bleeding and pseudoaneurysm post-PD. It may not only determine whether there is an aneurysm and determine its size and association with the parent artery, but also allow for interventional treatment to be performed immediately. In digital subtraction angiography, extravasation of contrast medium is a direct sign of bleeding. Indirect signs of bleeding include pseudoaneurysm, vasospasm and a rough vascular wall. A small pseudoaneurysm may be misdiagnosed as a ligated GDA stump or the diagnosis may be missed. When pseudoaneurysms in the major GDA or a branch are highly suspected, the catheter should be placed as close as possible to the hepatic artery for angiography and the injection rate, flow rate and pressure should also be checked. A location far from the GDA neck or a slow flow rate of the contrast agent may lead to a false-negative result on angiography. In certain patients, angiography may reveal difficulties in catheterization and not all causes of the bleeding may be identified; thus, exploration and endoscopic treatment are more appropriate for those patients with delayed PPH and unstable hemodynamics $(14,18)$. Among the 17 patients in this group, 1 patient had a suspected small pseudoaneurysm at the end of a small branch of the GDA on celiac angiography. When common hepatic artery angiography and amplified angiography were performed, the pseudoaneurysms and irregular parent artery were clearly displayed. In addition, attention should be paid to eliminate intestinal contents, intestinal gas overlap, motion artifacts and other interference to prevent misdiagnosis and missed diagnosis.

The common ways to deal with post-operative hemorrhage and pseudoaneurysm are surgery and endovascular management. The strategy during the surgical procedure is to find the parent artery of the pseudoaneurysm and ligate it with filaments or clamp it with titanium alloy. If PF is identified, pancreas-intestinal anastomosis may be performed simultaneously. Embolization, stent-graft implantation, stent-assisted coiling and balloon remodeling techniques are commonly used endovascular therapies. The covered stent increases the operative time and difficulty for patients with emergency bleeding (16), and PF may lead to re-occurrence of pseudoaneurysms at both ends of the stent. In addition, economic factors and the minor diameter of the parent artery are also important reasons for the limited application of covered stent. Due to the extensive anastomosis of digestive vessels, the possibility of re-bleeding after embolization is high, but it also associated with the absence of large-area tissue necrosis after embolization, and thus, it is widely used in clinical practice (37).

The embolization method of pseudoaneurysm is mainly based on its location, size and diameter of the parent artery $(13,16)$. In addition, the presence of sufficient landing zones and lateral branches also determines the choice of embolization method. Microcoils are the preferred and most widely used tools for embolization of a pseudoaneurysm. Various techniques of coil embolization for pseudoaneurysm are widely used. Pseudoaneurysms in the main GDA were similar to those in the splenic and hepatic arteries observed in the present study. The exclusion technique is recommended for embolization, but the possibility of stent implantation to maintain patency of the parent artery may reduce complications. However, in an emergency, coil embolization is worth using to prevent the occurrence of unfavorable events (38). The technique of proximal embolization is widely used in the treatment of pseudoaneurysm at the end of small branches. Sac packing is used for saccular pseudoaneurysms with a narrow neck, which allows for maintaining the patency of the parent artery. However, pseudoaneurysms have a risk of secondary rupture (39). Hur et al (40) compared two embolization techniques in the treatment of GDA stumps and concluded that the rupture rate of the pseudoaneurysm treated by the packing technique (selective embolization of the GDA stump and/or pseudoaneurysm sparing hepatic arterial flow) was higher than that of the sandwich technique (embolization of the hepatic artery proximal and distal to the GDA stump). Ligation of the GDA and lymph node dissection during PD may lead to the formation of pseudoaneurysm of the GDA (40). The strategy varies slightly depending on the length of the GDA stump. In the present study, it was assumed that if the GDA stump exhibited a beak-like change from the normal shape and the hepatic artery was not damaged, no embolization of the stump was required; however, a sac-like change, regardless of its length, required intervention to prevent secondary rupture. If the stump is long, a microcatheter may be inserted coaxially and embolized by microcoil packing without affecting the blood flow of the liver. If the GDA stump cannot be embolized using the coil packing technique, it is essential to prevent complications including coil migration when hepatic artery embolization is performed with the exclusion technique or sandwich technique as a last resort. In this case, it is important to choose a microcoil with the correct diameter. However, due to bleeding, hypotension and the use of vasoconstrictor drugs, visceral arteries frequently constrict or spasm. If minor diameter coils are used, distal migration and re-bleeding may occur. Similarly, if it is too large, it may lead to artery rupture. Therefore, it may be reasoned that the ratio of the coil diameter to parent artery diameter should be at least 1.2-1.5 to stabilize the coil at the orifice of the pseudoaneurysm. The coil should be stabilized in the aneurysmal neck of a pseudoaneurysm, even if the coil packing is poor. In the present study, there was a case of GDA residual pseudoaneurysm (case no. 4; Table I), which was embolized by the sac packing technique. During the extraction of the catheter after treatment, the patient complained of abdominal pain, which was accompanied by a significant drop in blood pressure. Re-angiography confirmed active bleeding, which was considered to be caused by rupture of pseudoaneurysm. Therefore, the sandwich technique was adopted for immediate treatment. However, the methods and strategies of embolization in this case were initially inappropriate and resulted in irreversible technical complications. Sac packing and sandwich technique resulted in pseudoaneurysm rupture and hepatic artery occlusion respectively, which were inappropriate for this patient. Covered stent placement and assisted coiling are more suitable for this type of patient, who had mechanically injured arteries from clamping, stretching and removal of lymph nodes along the vessels during the operation (41). Fluid embolization materials have been widely used in the treatment of pseudoaneurysm, but the risk of ectopic embolization is higher than that of coil 
embolization. The combination of liquid embolization materials with ectopic embolization is a good approach $(42,43)$. With the continuous improvement of technology, various approaches are available for the management of pseudoaneurysms. The endovascular approach, percutaneous approach and endoscopic ultrasonography are widely used in recent years (44). In the present study, the clinical success rate was higher (74 vs. $94.1 \%$ ) and the re-bleeding rate was lower than that reported by Pottier et al (45) (0 vs. 29\%), which may have been due to the embolic materials used, the embolic methods adopted and different criteria for clinical success. The combination of multiple embolic materials and methods may improve the success rate and reduce complications and associated mortality. Although procedures of standard clinical practice were adopted and a higher clinical success rate and lower mortality rate $(5.9 \%, 1 / 17)$ were achieved in the present study as compared with those in certain other studies; the mortality rate reported in the literature ranges from 8.69 to $12.5 \%(40,46)$. The mortality rate in the present study was still low, as it was within the threshold set by the recommendations of guidelines, according to which the overall mortality should be controlled between 2.2 and $12.8 \%$ (suggested threshold, 10\%) (15). The mortality in one patient (case no. 4; Table I) was caused by our decision-making mistakes. The exclusion/isolation technique or sandwich technique is more suitable for residual saccular pseudoaneurysm of the GDA stump, rather than the sac packing technique. A detailed analysis of angiography images and scientific implementation measures may avoid such incidents.

Of note, the present study had certain limitations. Due to the nature of the patients' work and economical status, was is difficult to perform a long-term follow-up and the data were incomplete. In addition, the type of medical insurance and the opinions of family members are important factors that influence the choice of treatment. In the present study, taking individuals from low income and low education backgrounds into consideration and that the patients only received coil embolization, selection bias may exist. Due to difficult catheterization of affected arteries and high risk of migration of coils, surgical exploration may be more appropriate for such patients. Furthermore, the present study was a retrospective analysis and no comparative analysis was performed. The small sample size is another shortcoming of the present study.

In conclusion, there are abundant collateral vessels in pseudoaneurysm of the digestive tract and the possibility of organ necrosis after coil embolization is lower compared with that after stent placement. A variety of embolization techniques may be applied for the treatment of pseudoaneurysm after PD, which have high technical and clinical success rates and small trauma. Coil embolization is recommended in cases of emergency but care should be taken to avoid serious technical complications.

\section{Acknowledgements}

Not applicable.

\section{Funding}

No funding was received.

\section{Availability of data and materials}

The datasets used and/or analyzed during the current study are available from the corresponding author on reasonable request.

\section{Authors' contributions}

HX and CJ made substantial contributions to the conception and design of the study and wrote the original draft of the manuscript. Jie Z, XLM, Jing Z, LY and YJR were responsible for data acquisition and conducted data analysis and interpretation. HX revised it critically for important intellectual content. All authors read and approved the final version of the manuscript.

\section{Ethics approval and consent to participate}

The Ethics Committee of the Affiliated Hospital of North Sichuan Medical College approved the present study.

\section{Patient consent for publication}

Not applicable.

\section{Competing interests}

The authors declare that they have no competing interests.

\section{References}

1. McEvoy SH, Lavelle LP, Hoare SM, O'Neill AC, Awan FN, Malone DE, Ryan ER, McCann JW and Heffernan EJ: Pancreaticoduodenectomy: Expected post-operative anatomy and complications. Br J Radiol 87: 20140050, 2014.

2. Qin K, Wu Z, Jin J, Shen B and Peng C: Internal hernia following robotic assisted pancreaticoduodenectomy. Med Sci Monit 24: 2287-2293, 2018.

3. Umemura A, Nitta H, Takahara T, Hasegawa Y and Sasaki A: Current status of laparoscopic pancreaticoduodenectomy and pancreatectomy. Asian J Surg 41: 106-114, 2018.

4. Sato A, Masui T, Nakano K, Sankoda N, Anazawa T, Takaori K, Kawaguchi Y and Uemoto S: Abdominal contamination with candida albicans after pancreaticoduodenectomy is related to hemorrhage associated with pancreatic fistulas. Pancreatology 17 : 484-489, 2017.

5. Wang M, Cai H, Meng L, Cai Y, Wang X, Li Y and Peng B: Minimally invasive pancreaticoduodenectomy: A comprehensive review. Int J Surg 35: 139-146, 2016.

6. Ammori BJ and Ayiomamitis GD: Laparoscopic pancreaticoduodenectomy and distal pancreatectomy: A UK experience and a systematic review of the literature. Surg Endosc 25: 2084-2099, 2011.

7. Smits FJ, van Santvoort HC, Besselink MG, Batenburg MCT, Slooff RAE, Boerma D, Busch OR, Coene PPLO, van Dam RM, van Dijk DPJ, et al: Management of severe pancreatic fistula after pancreatoduodenectomy. JAMA Surg 152: 540-548, 2017.

8. Morita S, Tajima T, Yamazaki H, Sonoyama Y, Nishina Y, Kenji O, Takagi T, Kondo T, Tanabe K and Sakai S: Early postoperative screening by contrast-enhanced CT and prophylactic embolization of detected pseudoaneurysms prevents delayed hemorrhage after partial nephrectomy. J Vasc Interv Radiol 26: 950-957, 2015

9. Kendrick ML, van Hilst J, Boggi U, de Rooij T, Walsh RM, Zeh HJ, Hughes SJ, Nakamura Y, Vollmer CM, Kooby DA, et al: Minimally invasive pancreatoduodenectomy. HPB (Oxford) 19: 215-224, 2017.

10. Kim E: Embolization therapy for refractory hemorrhage in patients with patients with chronic subdural hematomas. World Neurosurg 101: 520-527, 2017. 
11. Liu Y, Wang J, Lin L, Sang C, Lin Z, Pan Y and Fu X: Clinical study on complications of intracranial reptured aneurysm embolization by stent-assisted coil. Med Sci Monit 24: 8115-8124, 2018.

12. Wang Y and Jia P: The role of metallic clips in transcatheter intravascular embolization for non-variceal upper gastrointestinal bleeding cases receiving unmnageable endoscopic therapy: A retrospective cohort study. Int J Surg 58: 26-30, 2018.

13. Madhusudhan KS, Venkatesh HA, Gamanagatti S, Garg P and Srivastava DN: Interventional radiology in the management of visceral artery pseudoaneurysms: A review of techniques and embolic materials. Korean J Radiol 17: 351-363, 2016.

14. Wente MN, Veit JA, Bassi C, Dervenis C, Fingerhut A, Gouma DJ, Izbicki JR, Neoptolemos JP, Padbury RT, Sarr MG, et al: Postpancreatectomy hemmorrhage (PPH): An international study group of pancreatic surgery (ISGPS) definition. Surgery 142: 20-25, 2007

15. Angle JF, Siddiqi NH, Wallace MJ, Kundu S, Stokes L, Wojak JC and Cardella JF; Society of Interventional Radiology Standards of Practice Committee: Quality improvement guidelines for percutaneous transcatheter embolization: Society of interventional radiology standards of practice committee. J Vascu Interv Radiol 21: 1479-1486, 2010

16. You Y, Choi SH, Choi DW, Heo JS, Han IW, Han S, Shin SW, Park KB, Park HS, Cho SK and Han SH: Long-term clinical outcomes after endovascular management of ruptured pseudoaneurysm in patients undergoing pancreaticoduodenectomy. Ann Surg Treat Res 96: 237-249, 2019.

17. Meyers PM, Shcumacher HC, Higashida RT, Derdeyn CP, Nesbit GM, Sacks D, Wechsler LR, Bederson JB, Lavine SD and Rasmussen P: Reporting standards for endovascular repair of saccular intracranial cerebral aneurysms. AJNR Am J Neuroradiol 31: E12-E24, 2010.

18. Hassold N, Wolfschmidt F, Dierks A, Klein I, Bley T and Kickuth R: Effectiveness and outcome of endovascular therapy for late-onset postpancreatectomy hemorrhage using covered stents and embolization. J Vasc Surg 64: 1373-1383, 2016.

19. Ginat DT, Saad WE and Turba UC: Transcatheter renal artery embolization: Clinical applications and techniques. Tech Vasc Interv Radiol 12: 224-239, 2009.

20. Belli AM, Markose G and Morgan R: The role of interventional radiology in the management of abdominal visceral artery aneurysms. Cardiovasc Intervent Radiol 35: 234-243, 2012.

21. Cordova AC and Sumpio BE: Visceral artery aneurysms and pseudoaneurysms-should they all be managed by endovascular techniques? Ann Vasc Dis 6: 687-693, 2013.

22. Xia W, Zhou Y, Lin Y, Yu M, Yin Z, Lu X, Hou B and Jian Z: A predictive risk scoring system for clinically relevant pancreatic fistula after pancreaticoduodenectomy. Med Sci Monit 24: 5719-5728, 2018

23. Dumitru R, Carbunaru A, Grasu M, Toma M, Ionescu M and Dumitrascu T: Pseudoaneurysm of the splenic artery-an uncommon cause of delayed hemorrhage after pancreaticoduodenectomy. Ann Hepatobiliary Pancreat Surg 20: 204-210, 2016.

24. Gao F, Li J, Quan S, Li F, Ma D, Yao L and Zhang P: Risk factors and treatment for hemorrhage after pancreaticoduodenectomy: A case series of 423 patients. Biomed Res Int 2016: 2815693, 2016.

25. Schäfer M, Heinrich S, Pfammatter T and Clavien PA Management of delayed major visceral arterial bleeding after pancreatic surgery. HPB (Oxford) 13: 132-138, 2011

26. Feng J, Chen YL, Dong JH, Chen MY, Cai SW and Huang ZQ: Post-pancreaticoduodenectomy hemorrhage: Risk factors, managements and outcomes. Hepatobiliary Pancreat Dis Int 13: 513-522, 2014

27. Hatzaras I, George N, Muscarella P, Melvin WS, Ellison EC and Bloomston M: Predictors of survival in periampullary cancers following pancreaticoduodenectomy. Ann Surg Oncol 17: 991-997, 2010

28. Topal B, Fieuws S, Aerts R, Weerts J, Feryn T, Roeyen G, Bertrand C, Hubert C, Janssens $M$ and Closset J; Belgian Section of Hepatobiliary and Pancreatic Surgery: Pancreaticojejunostomy versus pancreaticogastrostomy reconstruction after pancreaticoduodenectomy for pancreatic or periampullary tumours A multicentre randomised trial. Lancet Oncol 14: 655-662, 2013

29. Saad NE, Saad WE, Davies MG, Waldman DL, Fultz PJ and Rubens DJ: Pseudoaneurysms and the role of minimally invasive techniques in their management. Radiographics 25 (Suppl 1): S173-S189, 2005.
30. Gabelmann A, Görich J and Merkle EM: Endovascular treatment of visceral artery aneurysms. J Endovasc Ther 9: 38-47, 2002.

31. Kamarajah SK: Pancreaticoduodenectomy for periampullary tumours: A review article based on surveillance, end results and epidemiology (SEER) database. Clin Transl Oncol 20: 1153-1160, 2018.

32. Pedrazzoli S and Sperti C: Prevention of clinically-relevant postoperative pancreatic fistula after pancreticoduodenectomy. Ann Surg 269: e7-e8, 2019.

33. Chadha $\mathrm{M}$ and Ahuja C: Visceral artery aneurysms: Diagnosis and percutaneous management. Semin Intervent Radiol 26: 196-206, 2009.

34. Yekebas EF, Wolfram L, Cataldegirmen G, Habermann CR, Bogoevski D, Koenig AM, Kaifi J, Schurr PG, Bubenheim M, Nolte-Ernsting C, et al: Postpancreatectomy hemorrhage: Diagnosis and treatment: An analysis in 1669 consecutive pancreatic resections. Ann Surg 246: 269-280, 2007.

35. Jesinger RA, Thoreson AA and Lamba R: Abdominal and pelvic aneurysms and pseudoaneurysms: Imaging review with clinical, radiologic, and treatment correlation. Radiographics 33: E71-E96, 2013

36. Dohan A, Dautry R, Guerrache Y, Fargeaudou Y, Boudiaf M, Le Dref O, Sirol M and Soyer P: Three-dimensional MDCT angiography of splanchnic arteries: Pearls and pitfalls. Diagn Interv Imaging 96: 187-200, 2015.

37. Guo J, Yu J, Zhang Q and Song X: Clinical efficacy and safety of uterine artery embolization (UAE) versus laparoscopic cesarean scar pregnancy debridement surgery (LCSPDS) in treatment of cesarean scar pregnancy. Med Sci Monit 24: 4659-4666, 2018.

38. Künzle S, Glenck M, Puippe G, Schadde E, Mayer D and Pfammatter T: Stent-graft repairs of visceral and renal artery aneurysms are effective and result in long-term patency. J Vasc Interv Radiol 24: 989-996, 2013

39. Sueyoshi E, Sakamoto I, Nakashima K, Minami K and Hayashi K: Visceral and peripheral arterial pseudoaneurysms. AJR Am J Roentgenol 185: 741-749, 2005.

40. Hur S, Yoon CJ, Kang SG, Dixon R, Han HS, Yoon YS and Cho JY: Transcatheter arterial embolization of gastroduodenal artery stump pseudoaneurysms after pancreaticoduodenectomy: Safety and efficacy of two embolization techniques. J Vasc Interv Radiol 22: 294-301, 2011

41. Kulkarni CB, Moorthy S, Pullara SK and Kannan RR: Endovascular treatment of aneurysm of splenic artery arising from splenomesentric trunk using stent graft. Korean J Radiol 14: 931-934, 2013.

42. Madhusudhan KS, Gamanagatti S, Garg P, Shalimar, Dash NR, Pal S, Peush S and Gupta AK: Endovascular embolization of visceral artery pseudoaneurysms using modified injection technique with N-butyl cyanoacrylate glue. J Vasc Interv Radiol 26 : $1718-1725,2015$.

43. Leyon JJ, Littlehales T, Rangarajan B, Hoey ET and Ganeshan A: Endovascular embolization: Review of currently available embolization agents. Curr Probl Diagn Radiol 43: 35-53, 2014.

44. Piasek E, Sojka M, Kuczyńska M, Światłowski $Ł$, Drelich-Zbroja A, Furmaga O and Jargiełło T: Visceral artery aneurysms-classification, diagnosis and treatment. J Ultrason 18: 148-151, 2018.

45. Pottier E, Ronot M, Gaujoux S, Cesaretti M, Barbier L, Sauvanet A and Vilgrain V: Endovascular management of delayed post-pancreatectomy haemorrhage. Eur Radiol 26: 3456-3465, 2016

46. Lee HG, Heo JS, Choi SH and Choi DW: Management of bleeding from pseudoaneurysms following pancreaticoduodenectomy. World J Gastroenterol 16: 1239-1244, 2010.

This work is licensed under a Creative Commons Attribution-NonCommercial-NoDerivatives 4.0 International (CC BY-NC-ND 4.0) License. 